\title{
Studies on Yield Performance with Special Emphasis on Early Transplanted Condition of Elite Rice (Oryza sativa L.) Genotypes at Bastar Condition
}

\author{
Sunil Kumar, Sonali Kar*, J. L. Salam, N. C. Mandawi and D. P. Singh \\ S G College of Agriculture and Research Station Kumhrawand, Jagdalpur, Bastar, \\ Chhattisgarh (India) \\ *Corresponding author
}

\section{Keywords \\ Yield, Transplanted condition, Elite, Rice}

\section{Article Info}

Accepted:

20 October 2020

Available Online:

10 November 2020

\section{A B S T R A C T}

Rice (Oryza sativa L.) belongs to the family Poaceae it is one of the principle food crop in the world and is a necessary food for all in same or the other way. Present study sixty four rice genotypes, along with checks, on the basis of six qualitative and nine qualitative characters. Analysis of variance for quantitative and qualitative characters showed for different characters. The result of analysis of variance indicated that the mean sum of squares due to the genotype were highly significant for the quantitative character studies i.e. days to $50 \%$ flowering ,plant height, $(\mathrm{cm})$, number of panicles, panicle length, test weight, number of effective tiller, spikelet fertility, harvest index, grain yield, grain length, grain width, L/B ratio and milling \%. High magnitude of coefficient of variation (more than $21 \%$ ) in the entire genotypes was observed for Harvest index $(21.75 \%$ ). Moderate magnitude of coefficient of variation (10-20\%) was observed for grain yield $(25.02 \%)$. The highest heritability was recorded for days to $50 \%$ flowering followed by, \%), L/B ratio, plant height, and grain length, evaluated against in stem borer infestation. Total sixty four genotypes were selected for the present investigation. Details of genotype are given in. Out of twenty major insect pests reported by several workers in rice one insect pest namely stem borer were recorded as major insect pests while others were observed as visiting pest. For the forty five genotypes highly resistance six genotypes resistance and thirteen genotypes are moderately resistance. In leaf blast infestation out of Sixty four genotypes from the occurrence of leaf blast infestation and 0.00-1.0\% percent disease incidence (PDI) score while nine genotypes Highly resistant exhibited 2.0-10.0\% PDI score thirty three genotypes Resistant was 11.0-20.0 \% PDI score, twenty two genotypes Moderately resistant are. The desirable traits from these hopeful sources can be merged into elite entries with higher yield potential or exploited for advanced genetic analysis studies. The Correlation coefficient analysis is the index of association between two variables. These have been dealt in all possible combination for important quantitative character at phenotypic and genotypic levels are presented path analysis to estimate the direct and indirect effect of various characters towards seed yield per plant. From the thirteen characters included in the study nine characters showed positive direct effect towards seed yield per plant. The genetic divergence analysis using Mahalanobi's statistic provides a useful tool for measuring the inherent diversity in genotypes with respect to the characters considered together. It also provides a quantitative measure of association between geographic and genetic diversity based on generalized distance. 


\section{Introduction}

"Rice is the most important human food crop in the world, directly feeding more people than any other crop. It is also the staple food across Asia where around half of the world's poorest people live. It is widely grown in tropical and subtropical regions. Rice found in Asia, America and Europe belongs to Oryza sativa and varieties grown in West Africa belong to Oryza glaberrima. The sativa rice species are commonly divided in to three subspecies namely; Indica, Japonica and Javanica. Rice belongs to the genus Oryza and has two cultivated and 22 wild species. Rice has also fed more people over a longer time than has any other crop. It is spectacularly diverse, both in the way it is grown and how it is used by humans. "The domestication of rice ranks as one of the most important developments in history and now thousands of rice varieties are cultivated on every continent except Antarctica. Rice is grown under many different conditions and production systems, but submerged condition water is the most common method used worldwide. Rice is the only cereal crop that can grow for long periods of time in standing water. $57 \%$ of rice is grown on irrigated land, $25 \%$ on rain fed lowland, $10 \%$ on the uplands, and $6 \%$ in deepwater and $2 \%$ in tidal wet lands (Bandi et al., 2018). "In Chhattisgarh, rice occupies an area of 3.76 mha with production and productivity of $4.73 \mathrm{mt}$ and $1256 \mathrm{~kg} / \mathrm{ha}$, respectively (Ministry of Agriculture \& Farmers Welfare, 2018). In Chhattisgarh, it is mainly grown under rained ecosystem, which covers about 95 per cent cropped area of Chhattisgarh plain, Bastar plateau and Northern hill zones, respectively. The Central plains of Chhattisgarh are known as rice bowl of central India" (Shrivastava et al., 2012).

By transplanting paddy during $1^{\text {st }}$ week of July the production of paddy can be increased and incidence of insect pest and diseases may reduce as well as the soil moisture may be utilized. Also pollination is effective when the temperature is less. As water scarcity is increasing water quality is declining and uncertainties caused by climate change and climate variability are increasing, the use of crop models and simulation of crop response to such changes can be an emergent and efficient solution to help identify the impacts and subsequent best management practices. In Chhattisgarh, about $82 \%$ population depends on agriculture for their livelihood. The sensitivity of rice to high temperature varies with growth phase, an increase in day/night temperature and genotype (Yoshida et al., 1981). Planning and execution of any breeding program for improvement on quantitative traits depends on magnitude of genetic variability.

\section{Materials and Methods}

The experiment was carried out at Research cum Instructional Farm, S.G. College of Agriculture and Research Station Kumhrawand, Jagdalpur, Bastar, Chhattisgarh, India. The experimental materials comprised of sixty four genotypes of rice and one popular standard checks. The experiment was conducted during Kharif 2019 in RCBD Design to assess the studies on yield performance with special emphasis on early transplanted condition of elite rice (Oryza sativa L.) Genotypes at Bastar condition among the sixty four genotypes of rice (Oryza sativa L.) and one popular standard checks namely Samleshwari. The observations on various agro-morphological characters including qualitative and quantitative characters of rice were recorded $v i z$. days to $50 \%$ flowering, plant height, number of panicle $/ \mathrm{m}^{2}$, panicle length, number of effective tillers/plant, spikelet fertility, test weight, grain breadth, grain length, grain length breadth ratio, harvest index, grain 
yield/ha., milling \% incidence of stem borer, incidence of rice blast. The data recorded on sixty four genotypes of rice and one popular standard checks for different quantitative characters and quality characters were subjected to the statistical analysis.

\section{Spikelet fertility}

Percentage it was computed from count of fertile and sterile spikelet of the main tiller panicle as per the following formula:

Spikelet fertility $\%=\frac{\text { Number of sterile spikelet }}{\text { Total number of spikelet }} \times 100$

\section{Milling percentage}

The hulled samples were milled and weight of milled grains was recorded. The

Formula is as follow:

Milling percentage $=\frac{\text { Weight of the polished kernel }}{\text { Weight of paddy }} \times 100$

\section{Rice stem borer incidence}

Dead heart is a dried central shoot of a tiller on the rice plant observed during the vegetative (seedling to maximum tillering) stage that has been damaged by stem borer. Dead hearts (dried tillers) at tillering stage in each hill were counted and recorded.

Dead heart $\% \frac{\text { Number of dead heart/hill }}{\text { Total number of tiller } / \text { hill }} \times 100$

\section{Percent disease incidence}

The Percent Disease Incidence (PDI) was determined by observed and recorded disease scale of blast and brown spot.

$$
\mathrm{PDI}=\frac{\text { Total sum of disease ratings }}{\text { Total number of ratings }} \times 100
$$

\section{Results and Discussion}

To establish distinctiveness among rice genotypes, qualitative characters have been used. Qualitative traits are considered as yield performance in the identification of genotypes of rice, because they are less influenced by environment. In the present investigation, out of four qualitative characters and observed, grain length, grain width, L/B ratio, milling $\%$.

Recorded highest variation followed by Thus, characterization of Germplasm genotypes establishes distinctiveness among rice genotypes. It is not only important for utilizing the appropriate attribute based donors in breeding programmes, but also essential in the present era for protecting the unique rice.

Coefficient of variation truly provides a relative measure of variability among different attributes. In the present study wide range of genetic variability was observed for most of the quantitative traits.

High magnitude of coefficient of variation (more than $21 \%$ ) in the entire genotypes was observed for harvest index (21.75\%). Moderate magnitude of coefficient of variation (10-20\%) was observed for grain yield $(25.02 \%)$ and whereas low magnitude of coefficient of variation $(<10 \%)$ had been observed for days to $50 \%$ flowering $(6.66 \%)$ milling percentage $(5.44 \%)$ panicle length $(17.70 \%) \mathrm{L} / \mathrm{B}$ ratio (13.69\%) grain length (9.12\%) plant height (11.39\%) and number of panicle $(19.23 \%)$ grain width $(9.47 \%)$ and number of effective tillers $(17.48 \%)$ spikelet fertility (9.06\%) test weight (20.10\%) Similarly findings of high amount of coefficient of variation for effective tillers per plant were observed by Singh et al., (2010) and Badri et al., (2015). 
Int.J.Curr.Microbiol.App.Sci (2020) 9(11): 2655-2661

Table.1 Correlation for different quantitative and qualitative traits

\begin{tabular}{|c|c|c|c|c|c|c|c|c|c|c|c|c|c|c|}
\hline Traits & $\mathbf{P H}$ & NFT & SF & PL & NOP & TW & HI & M \% & GL & GW & LB & DFF & GY & GY \\
\hline PH & & 0.02 & -0.07 & $0.25 *$ & 0.04 & 0.20 & -0.20 & 0.24 & 0.19 & 0.08 & 0.19 & 0.23 & $0.30 *$ & $0.30 *$ \\
\hline NFT & & & -0.06 & 0.05 & -0.02 & -0.09 & 0.03 & -0.07 & 0.01 & -0.07 & -0.08 & 0.04 & -0.07 & -0.07 \\
\hline SF & & & & -0.05 & -0.26 & 0.16 & 0.11 & -0.18 & -0.16 & $0.25 *$ & $-0.36 * *$ & -0.14 & -0.02 & -0.02 \\
\hline PL & & & & & -0.20 & 0.13 & 0.23 & -0.17 & 0.07 & 0.02 & 0.13 & 0.17 & 0.10 & $0.10 *$ \\
\hline NOP & & & & & & -0.22 & $-0.27 *$ & 0.07 & -0.13 & -0.18 & 0.02 & 0.24 & 0.14 & $0.14 *$ \\
\hline TW & & & & & & & $0.28 *$ & 0.05 & 0.21 & $0.59 * *$ & $-0.32 * *$ & -0.21 & 0.22 & $0.22 *$ \\
\hline HI & & & & & & & & 0.02 & 0.08 & $0.29 *$ & -0.23 & -0.10 & $0.28 *$ & $0.28 *$ \\
\hline M \% & & & & & & & & & 0.08 & 0.07 & -0.02 & 0.04 & $0.34 * *$ & $0.34 * *$ \\
\hline GL & & & & & & & & & & 0.03 & $0.69 * *$ & 0.03 & 0.01 & 0.01 \\
\hline GW & & & & & & & & & & & $-0.54 * *$ & -0.12 & 0.23 & 0.23 \\
\hline LB Ratio & & & & & & & & & & & & 0.19 & -0.14 & -0.14 \\
\hline DFF & & & & & & & & & & & & & $0.30^{*}$ & $0.30 *$ \\
\hline GY & & & & & & & & & & & & & & 1 \\
\hline
\end{tabular}

$\mathrm{PH}=$ Plant height, NFT $=$ Number of effective tiller, SF $=$ Spikelet fertility, $\mathrm{PL}=$ Panicle length, NOP $/ \mathrm{m}^{2}=\mathrm{Number}$ of panicle $/ \mathrm{m}^{2}, \mathrm{TW}=\mathrm{Test}$ weight, $\mathrm{M} \%=$ Milling $\%, \mathrm{GL}=$ Grain length, $\mathrm{GW}=$ Grain width, $\mathrm{L} / \mathrm{B}$ ratio $=$ grain length: grain width ratio, DFF $=$ Days to $50 \%$ flowering, $\mathrm{GY} / \mathrm{ha} .=$ grain yield $/ \mathrm{ha}$. 
Int.J.Curr.Microbiol.App.Sci (2020) 9(11): 2655-2661

Table.2 Path coefficients showing direct and indirect effects of different characters on grain yield/ ha

\begin{tabular}{|c|c|c|c|c|c|c|c|c|c|c|c|c|c|}
\hline Traits & PH & NFT & SF & PL & NOP & TW & HI & М \% & GL & GW & LB Ratio & DFF & GY \\
\hline PH & 0.22 & 0.01 & -0.09 & -0.01 & 0.01 & 0.05 & -0.01 & -0.01 & -0.02 & 0.01 & 0.02 & 0.03 & $0.30 *$ \\
\hline NFT & 0.07 & 0.14 & -0.08 & -0.01 & -0.09 & -0.02 & 0.04 & 0.03 & -0.01 & -0.01 & -0.07 & 0.07 & -0.07 \\
\hline SF & -0.01 & -0.03 & 0.01 & 0.03 & -0.08 & 0.03 & 0.04 & 0.08 & 0.01 & 0.05 & -0.03 & -0.03 & -0.02 \\
\hline PL & 0.06 & 0.03 & -0.07 & -0.03 & -0.07 & 0.02 & 0.09 & 0.08 & -0.01 & 0.08 & 0.01 & 0.02 & 0.10 \\
\hline NOP & 0.01 & -0.01 & -0.09 & 0.05 & 0.23 & -0.05 & -0.01 & -0.03 & 0.01 & -0.03 & 0.02 & 0.03 & 0.14 \\
\hline TW & 0.05 & -0.04 & 0.02 & -0.03 & -0.07 & 0.02 & 0.01 & -0.02 & -0.02 & 0.01 & -0.03 & -0.03 & 0.22 \\
\hline HI & -0.05 & 0.01 & 0.01 & -0.06 & -0.04 & 0.01 & 0.14 & -0.01 & -0.01 & 0.01 & -0.02 & -0.01 & $0.28 *$ \\
\hline M \% & 0.06 & -0.04 & -0.02 & 0.04 & 0.05 & 0.03 & 0.09 & -0.24 & -0.01 & 0.01 & -0.02 & 0.07 & $0.34 * *$ \\
\hline GL & 0.05 & 0.08 & -0.02 & -0.02 & -0.05 & 0.04 & 0.03 & -0.03 & -0.37 & 0.01 & 0.06 & 0.06 & 0.01 \\
\hline GW & 0.02 & 0.06 & 0.03 & -0.06 & -0.06 & 0.01 & 0.01 & -0.03 & -0.02 & 0.22 & -0.05 & -0.02 & 0.23 \\
\hline LB Ratio & 0.05 & -0.04 & -0.04 & -0.03 & 0.01 & -0.01 & -0.01 & 0.01 & -0.05 & -0.01 & 0.20 & 0.03 & -0.14 \\
\hline DFF & 0.06 & 0.02 & -0.01 & -0.04 & 0.09 & 0.06 & -0.04 & -0.02 & -0.02 & -0.02 & 0.02 & 0.29 & $0.30 *$ \\
\hline GY & 0.08 & -0.03 & 0.08 & -0.02 & 0.05 & 0.01 & 0.01 & -0.01 & -0.01 & 0.04 & -0.01 & 0.04 & 1 \\
\hline
\end{tabular}

$\mathrm{PH}=$ Plant height, NFT $=$ Number of effective tiller, $\mathrm{SF}=$ Spikelet fertility, $\mathrm{PL}=$ Panicle length, NOP $/ \mathrm{m}^{2}=\mathrm{Number}$ of panicle $/ \mathrm{m}^{2}, \mathrm{TW}=\mathrm{Test}$ weight, $\mathrm{M} \%=$ Milling $\%, \mathrm{GL}=$ Grain length, $\mathrm{GW}=$ Grain width, $\mathrm{L} / \mathrm{B}$ ratio $=$ grain length: grain width ratio, DFF $=$ Days to $50 \%$ flowering, $\mathrm{GY} / \mathrm{ha} .=$ grain yield $/ \mathrm{ha}$. 
Correlation analysis revealed positive and highly significant correlation of total number of filled grains per panicle, number of grains per panicle, plant height and number of effective tiller per plant, harvest index, test weight, flag leaf length and days to maturity had positive and highly significant correlation with grain yield per plant. It indicates strong correlation of these traits with grain yield per plant and selection for these traits will be useful in improving grain yield. Positive correlation between desirable traits is favourable, because it helps in simultaneous improvement of both the characters. On the other hand, negative correlation will hinder the simultaneous expression of both characters with high values. In such situation some economic compromise has to be made (Table1).

Path coefficient analysis revealed that flag leaf length, days to maturity, plant height, number of effective tillers per plant, harvest index, and total number of grains per panicle had highly significant positive correlation with grain yield per plant as well as positive direct effect on grain yield per plant.

The total number of filled grains per panicle had significant positive correlation with grain yield per plant but exhibited very high negative direct effect on grain yield. In this situation, correlation is mainly due to indirect effects of the character through another component trait, so indirect causal factors are to be considered simultaneously for selection. According to the magnitude of the direct effects on grain yield, the order of yield components was direct selection for characters viz. plant height, number of effective tillers per plant, and harvest index which will be very effective for increasing the grain yield, hence they should be given consideration in the selection criteria (Table 2).

\section{Acknowledgements}

The author is thankful to the Department of Genetics and Plant Breeding S G College of Agriculture and Research Station Kumhrawand, Jagdalpur, (C.G.) IGKV, Raipur (Chhattisgarh).

\section{References}

Babu, R.V., Shreya, K., Dangi, K.S., Usharani, G., and Shankar, A.S. 2012. Correlation and Path Analysis Studies in popular Rice Hybrids of India. Int. J. Sci. Res. Pub., 2(3): 1-5.

Bandi, H. R. K., Satyanarayana, P.V., Babu, D.R., Chamundeswari, N., Rao, V. S., and Raju, S.K., (2018). Genetic variability estimates for yield and yield components traits and quality traits in rice (Oryza sativa L.). Int. J. Curr. Microbiol.App.Sci. 7(5), 551-559.

Hossain, M., Ansar, M.D., Hossain, M.D., 2017 Occurrence of Blast Disease in Ricein Bangladesh Ajas, 4(4): 74-80.

Hossain, S., Haque, M., Rahman, J., 2015 Genetic variability, Correlation and Path Coefficient Analysis of morphological traits in some Extinct Local Aman Rice (Oryza sativa L) ISSN. Volume 4(1): 2-6.

Khan, A.S., Imran, M. and Asfaq, M. 2015. Estimation of genetic variability and correlation for grain yield components in rice (Oryza sativa L.). AmericanEurasian journal of agriculture and environment science, 6(5): 585-590.

Kumar, S., Chauhan, M., P., Tomar, A., Kasana, R., K., Kumar, N., 2018 Correlation and path coefficient analysis in rice (Oryza sativa L.) TPI 7(6): 2026.

Kuyek, D., 2000. Blast, biotech and big business. Implications of corporate strategies on rice research in Asia. Retrieved from. 7(6): 22-28. 
Longkumer, I.Y., Singh, K.I., Singh, A. 2017 Efficacy of eco-friendly insecticides against yellow stem borer under kharif rice-crop ecosystem of Manipur valley TPI; 6(11): 19-21.

Madhavilatha, L., Reddi, M.S., Suneetha, Y. and Srinivas, T. 2005. Genetic Variability, Correlation and Path analysis for Yield and Quality Traits in Rice (Oryza sativa L.). Res. on Crops. 6(3): 527-534.

Mahajan, G., Bharaj, T.S. and Timsina, J. (2009). Yield and water productivity of rice as affected by time of transplanting in Punjab, India. Agricultural Water Management, 96: 525-32.

Naseem, I., Khan, A.S. and Akhter, M., 2014. Correlation and path coefficient studies of some yield related traits in rice (Oryza sativa L.). Int. J. Sci. and Res. Pub., 4(4): 1-5.
Nayak, R., Singh, V., Singh, A.K., Singh, P.K. 2016. Genetic variability, character association and path analysis of rice genotypes, Annals of Plant and Soil Research 18(2): 161-164.

Nirala Y.S., Chandrakar, G., Ghirtlahre, S.K., Sahu, C. 2015 Seasonal Incidence Of Yellow Stem Borer, Scirpophaga incertulas Walker In Midland Sri And Normal Transplanted Rice Ecosystem, 9(1\&2): 445-448.

Shrivastava, P., Saxena, R.R., Xalxo, M.S., Verulkar, S.B. 2012. Effect of High Temperature at Different Growth Stages on Rice Yield and Grain Quality Traits Journal of Rice Research 2012 Vol. 5 No.1 - 2 .

Yoshida, S. 1981. Physiological analysis of rice yields in fundamentals of rice crop science. Int. Rice Res. Ins., los Banos, Philippines. 42(1): 140-146.

\section{How to cite this article:}

Sunil Kumar, Sonali Kar, J. L. Salam, N. C. Mandawi and Singh, D. P. 2020. Studies on Yield Performance with Special Emphasis on Early Transplanted Condition of Elite Rice (Oryza sativa L.) Genotypes at Bastar Condition. Int.J.Curr.Microbiol.App.Sci. 9(11): 2655-2661. doi: https://doi.org/10.20546/ijcmas.2020.911.322 